\title{
Epidermolysis bullosa simplex with circinate migratory erythema
}

INSERM

\section{Source}

INSERM. (1999). Orphanet: an online rare disease and orphan drug data base.

Epidermolysis bullosa simplex with circinate migratory erythema. ORPHA:158681

Epidermolysis bullosa simplex with circinate migratory erythema (EBS-migr) is a basal subtype of epidermolysis bullosa simplex (EBS, see this term) characterized by belt-like areas of erythema with multiple vesicles and small blisters at the advancing edge of erythema. 